\title{
ESTÁGIO SUPERVISIONADO: NOVOS DESAFIOS AOS JOVENS TRABALHADORES DO ENSINO SUPERIOR
}

Lennon Gomes'; janaína Pereira Duarte Bezerra²

${ }^{1}$ Associação de Ensino e Cultura de Mato Grosso do Sul - AEMS, Arquitetura e Urbanismo, Três Lagoas MS. ${ }^{2}$ Universidade Estadual Paulista - UNESP, Mestrado em Educação, Campus de Presidente Prudente, SP.

\section{RESUMO}

A nova classe trabalhador/estudante nos revela no Brasil novas percepções sociais que buscam igualdade social através do ensino superior. O objetivo do artigo está em apresentar a realidade brasileira atual do jovem trabalhador no ensino superior, o acesso pelo esforço do jovem trabalhador e suas problemáticas e desafios que comprometem a qualidade do ensino, o estágio supervisionado como "uma barreira" deste acesso à educação, a importância do estágio supervisionado e breve discussão sobre novas possiblidades de ser realizado ou reestruturado no projeto político pedagógico das IES. Constatamos que as possibilidades garantidas por leis são muitas, porém, a maioria das IES ainda não garantem tal possibilidade que deve ser inserida nos projetos políticos pedagógicos dos cursos que lhe cabe, garantindo a formação democrática do trabalhador/estudante, em busca da igualdade social no Brasil.

Palavras chave: Estagio Supervisionado; Educação; Jovem Trabalhador.

\section{SUPERVISED INTERNSHIP: NEW CHALLENGES FOR YOUTH WORKERS IN HIGHER EDUCATION}

\begin{abstract}
The new class worker / student reveals new social perceptions in Brazil seeking social equality through higher education. The purpose of this paper is to present the current Brazilian reality of young workers in higher education, access by young worker effort and their problems and challenges that compromise the quality of education, supervised internship as a "barrier " of this access to education, the importance of supervised and brief stage discussion of new possibilities to be realized or restructured in the political pedagogical project of IES. We note that the possibilities guaranteed by laws are many, but most of the HEls have not warrant such a possibility that must be entered in pedagogical political projects of the courses that fits you, ensuring the democratic formation of worker / student, in search of social equality in Brazil.
\end{abstract}

Keywords: Supervised Internship; Education; Young Worker. 


\section{INTRODUÇÃO}

A obrigatoriedade do estágio supervisionado nos revela uma questão da atualidade muito presente entre os jovens com acesso ao ensino superior: o trabalho. Por norma de praticamente todos os cursos superiores ${ }^{1}$, o estágio é uma fase muito importante no contato direto com a profissão e ainda mais, traz a experiência da prática em concordância às teorias aplicadas em sala de aula, revelando a verdadeira identidade profissional deste aluno e situando-o a rotina profissional.

Para prosseguir aos estudos deste artigo, é importante ressaltar que iremos considerar toda a pesquisa voltada a Instituições de Ensino Superior Privadas, pelo fato de considerarmos que a problematização deste artigo se fundamenta na questão estágio/trabalho, portanto, a maior dificuldade está nesta relação associada as instituições privadas, pois o investimento ao ensino é bem maior se comparado as Instituições públicas (investimento por parte do discente).

Geralmente no último ano dos cursos superiores, o estágio supervisionado é uma disciplina que faz parte da grade curricular da maioria dos cursos superiores no Brasil. A problemática se faz assim: se o jovem (classe baixa) precisa trabalhar para ter o acesso à educação superior, como ele fará o estágio supervisionado?

Este trabalho teve objetivo em apresentar de maneira discursiva a realidade brasileira atual do jovem trabalhador no ensino superior, abordando: o acesso pelo esforço do jovem no ensino superior, suas problemáticas e desafios que comprometem a qualidade do ensino; o estágio supervisionado como "uma barreira" deste acesso à educação, cabendo-lhe realizá-lo ou não; e por fim; a importância do estágio supervisionado e o que ele representa para ser uma obrigatoriedade nos cursos superiores como parte estruturante do ensino a ser alcançado nos cursos, trazendo para a realidade atual do cenário brasileiro da educação.

\section{METODOLOGIA}

A pesquisa se iniciou por levantamentos bibliográficos em respeito à educação no Brasil, breve feita por leitura sistemática bibliométrica da educação no Brasil, onde procuramos relacionar a história do acesso e sua significante expansão através de artigos científicos que fundamentam a discussão. Partindo para a atualidade em relação ao acesso dos jovens de classe baixa ao ensino superior e seus meios que possibilitam tal acesso. Logo após, foi apresentado e discutido a questão do estágio supervisionado e sua relação com o Ensino, legislações vigentes e autores renomados (PICONEZ, 1991; BIANCHI; ALVARENGA; BIANCHI, 2002) da área da Educação trazendo questionamentos sobre tal prática, e por fim, apresentar e discutir a relação do jovem trabalhador e o estágio supervisionado no curso de ensino superior, abordando suas dificuldades, barreiras, possibilidades, baseado na legislação e apontamentos de estudiosos da área da Educação, assim como artigos científicos que contribuem para tal pensamento baseado em estudos de casos que contribuem para fomentar tal prática do estágio supervisionado e seus meios de alcançar a conclusão do curso superior como meio concluinte da pesquisa.

\section{ACESSO DO JOVEM À EDUCAÇÃO SUPERIOR NO BRASIL}

No Brasil, após a constituição de 1998, existem dois segmentos de instituições de ensino superior as públicas e as privadas. Conforme a Constituição de 1988, através de uma separação político administrativa e de ensino, delegando aos Municípios, ao Distrito Federal, aos Estados e a União as obrigatoriedades em seus diferentes níveis (ROTH, et al., 2013).

Roth et al. (2013) traz uma nova visão sobre o número de IES no Brasil após a nova LDB (Lei de Diretrizes e Bases da Educação Nacional) onde é possível verificar um crescimento no número de instituições públicas na ordem de 47,91\% em relação ao ano de 1999 . As instituições privadas

\footnotetext{
${ }^{1}$ Lei $11.788 / 2008$ em seu Art. $2^{\circ}$ prevê a obrigatoriedade ou não-obrigatoriedade dos estágios, conforme determinação das diretrizes curriculares da etapa, modalidade e área de ensino e do projeto pedagógico do curso.
} 
também apresentaram um crescimento significativo de $295,62 \%$ no mesmo período. Outra informação importante é que entre 1998 de 2011 o número total de IES no Brasil cresceu $443,48 \%$.

A educação, sobretudo a de nível superior, tornou-se, nas últimas décadas, um ativo altamente distintivo, capaz de promover o desenvolvimento. Para os indivíduos, o diploma de nível superior representa oportunidades de mobilidade social, por meio de carreiras profissionais mais promissoras quanto a realização pessoal, status social, direitos sociais (COMIN; BARBOSA, 2011).

O predomínio do período noturno no ensino superior (61,7\% do total de matrículas) é reflexo da situação econômica vivenciada pelo país das últimas décadas, pois permite mais facilmente que o estudante exerça uma atividade profissional remunerada (não necessariamente associada à sua área de interesse) durante os anos de curso de graduação, de forma a obter recursos financeiros para a realização do curso (TERRIBILI FILHO; NERY, 2009).

De todos os níveis de ensino, o superior é o único que vem apresentando aceleração em suas taxas de expansão, esboçando uma tendência exponencial. Há dois pontos de maior acentuação: no final dos anos 1990, seguindo as mudanças no marco regulatório que induziram a expansão no setor privado de ensino; e, a partir de 2005, sob o efeito das iniciativas governamentais (COMIN; BARBOSA, 2011).

Criada em 1977, a Lei $n^{\circ} 6.494$ (não regulamentada), dispõe sobre estágios de estudantes tanto do ensino superior quanto do ensino profissionalizante do $2^{\circ}$ grau e especial. Porém, em relação ao estágio citado como curricular, não aponta em nenhum momento como obrigatório, fazendo parte da grade curricular das instituições (BIANCHI; ALVARENGA; BIANCHI, 2002).

Na sequência, o Decreto $n^{\circ} 87.497 / 1982$, regulamenta a Lei $n^{\circ} 6.494$, caracterizando o estágio supervisionado como "estágio curricular", onde institui em seu art. 4으, alínea "a": "inserção do estágio curricular na programação didático-pedagógica; ", ou seja, neste momento as instituições passam a compor em sua grade o "estágio curricular". Porém, ainda não é especificado a sua obrigatoriedade (BIANCHI; ALVARENGA; BIANCHI, 2002).

$\mathrm{Na}$ instituição da nova LDB - Lei de Diretrizes e Bases da Educação Nacional de 1996 (Brasil, 2007), consta em seu Art. $1^{\circ}, 2^{\circ}$ parágrafo: “A educação escolar deverá vincular-se ao mundo do trabalho e à prática social", ou seja, restringe a metodologia da prática do estágio sendo realizada na comunidade em geral ou junto a pessoas jurídicas de direito público ou privado. Somente fica explicito à atividade estágio no Art. 82: "Os sistemas de ensino estabelecerão as normas de realização de estágio em sua jurisdição, observada a lei federal sobre a matéria", parte daí uma autonomia das instituições para estabelecer as normas de realização de estágio, não apresentando ainda uma obrigatoriedade, somente em seu art. 61, em seu parágrafo único, $2^{\circ}$ item, trata do estágio supervisionado para os profissionais da educação, se referindo a educação básica.

Como exemplifica claramente, o MEC aponta sendo o estágio supervisionado, portanto, de acordo com a legislação citada é, essencialmente, "estágio curricular", o qual pode assumir uma das seguintes formas: a) ou estágio profissional supervisionado, portanto, de caráter profissionalizante, direto e específico; b) ou estágio de contato com o mundo do trabalho, objetivando sua vinculação (LDB, Artigo 1으, §2으), em termos de desenvolvimento sociocultural; c) ou participação em empreendimentos ou projetos de interesse social ou cultural, assumindo a forma de atividades de extensão; d) ou estágio de prestação de serviço civil, obrigatório ou voluntário, que poderá vir a se constituir num eventual substitutivo ao atual serviço militar (BIANCHI; ALVARENGA; BIANCHI, 2002).

O caráter complementar, ou mesmo suplementar, conferido à Prática de Ensino/Estágio Supervisionado, uma teoria prevista no começo dos cursos e uma prática colocada no final deles sob forma de Estágio Supervisionado constituem a maior evidencia da dicotomia existente entre 
teoria e prática (PICONEZ, 1991). Ressaltamos que não nos limitamos somente a Licenciatura nas discussões, sendo também considerados os cursos de Bacharelado, objetivando um parâmetro comum entre estes e, por conseguinte, atingir um direcionador geral que engloba as questões do artigo em relação a nova percepção social do século XXI e suas considerações acerca de novas configurações Política Pedagógica dos cursos, sendo este último, abordado logo a frente.

\section{NOVAS PERSPECTIVAS DA EDUCAÇÃO NO ENSINO SUPERIOR BRASILEIRO}

Retornando rapidamente a um ponto fundamental acerca do estágio supervisionado, como aponta Kulcsar (1991), um dos elementos de que a Universidade dispõe e que poderia ser redimensionado é o Estagio Supervisionado, obrigatório em diversos cursos e que não são devidamente explorados.

O Planejamento Curricular na área educacional é o conjunto de ações planejadas para cada curso atingir os objetivos do processo ensino aprendizagem, portanto, contínuo e multidisciplinar. Gil (2006, p. 98) esclarece que antes da vigência da LDB da Educação Nacional (BRASIL, 2007), as instituições tinham pouca flexibilidade para elaborar seu planejamento curricular, e que com a legislação vigente, as instituições têm um maior nível de autonomia, o que permite que atendam a particularidades e especificidades regionais de sua localização; por outro lado, exigindo das instituições de ensino uma maior responsabilidade e criatividade (FURLANI, 1998).

Pontuemos as dificuldades que os estudantes trabalhadores possuem para empreender estágios profissionalizantes, dada a necessidade de abrir mão de um trabalho remunerado em troca de estágios que se caracterizam ausência de vínculo trabalhista (VARGAS; PAULA, 2013).

As mais baixas faixas de renda salarial ocorrem simultaneamente ao trabalho do graduando e as mais altas são produzidas sem ou com participação do trabalho do estudante. Situação duplamente injusta: a baixa renda surge junto e às custas do trabalho do estudante, comprometendo seu investimento escolar. Inversamente, a produção da alta renda independe do trabalho do graduando, totalmente liberado para estudar (VARGAS; PAULA, 2013).

Dentre os programas para permanência de estudantes nos cursos superiores, alguns são incentivos das políticas locais; algumas repartições públicas ou escolas trabalham com uma carga horária mais flexível, fazem convênio com a universidade para atendimento de estágio dos estudantes; outra política adotada são as parcerias para estágios nas empresas representativas particulares, além da política institucional de estágio dentro da própria universidade, em forma de bolsa de treinamento, ou iniciação científica, em tempo parcial de vinte horas semanais (CAVALCANTE, 2008).

Como apresentado anteriormente, existem em várias IES no Brasil diversas possibilidades de suprir esta prática/conhecimento profissional, porém, mesmo com a garantia sob diversas Leis, que deixam explícitas as relações de estágio supervisionado e em como podem ser realizadas, as IES parecem se acomodar e instituir em sua grade curricular o estágio supervisionado vinculado a empresas, como já discutido anteriormente. Este ato prejudica e vai contra a democracia do direito à educação instituído no país, assim como aponta Fazenda et al. (1991) sob o contexto do movimento de revisão da Didática que desde 1982 tem se afirmado e ampliado progressivamente, a questão da relação teoria/prática aparece com vigorosa reflexão crítica, buscando ações educativas mais comprometidas com a construção de uma escola adequada e democrática. Ato este que vem desfavorecendo ainda mais as classes baixas que são a grande maioria dos jovens que se encontram nesta atual condição.

O projeto político pedagógico do curso pode definir se é necessário ou não o estágio de acordo com a área de atuação e as próprias práticas profissionais do curso, ou seja, a autonomia garantida por lei possibilita uma maior flexibilidade na questão trabalho/estágio aqui discutida, sendo a principal referência das IES na garantia da qualidade de ensino e em respeito a novas configurações sociais dos jovens que buscam oportunidade de igualdade/crescimento social. 
Diversas formas apontadas anteriormente podem e devem ser inseridas no projeto político pedagógico nas IES e sendo melhor trabalhadas em relação ao estágio de contato com o mundo do trabalho, objetivando sua vinculação (LDB, Artigo $1^{\circ}$, $2^{\circ}{ }^{\circ}$ ), em termos de desenvolvimento sociocultural; ou participação em empreendimentos ou projetos de interesse social ou cultural, assumindo a forma de atividades de extensão; ou estágio de prestação de serviço civil, obrigatório ou voluntário. Garantindo assim, diversas formas de possibilidades na formação do cidadão no ensino superior, garantindo o acesso e permanência e, é claro, sua conclusão.

\section{CONSIDERAÇÕES FINAIS}

Apesar dos esforços federais, estaduais e municipais, o acesso ao ensino superior ainda se mostra frágil no Brasil, como mostra diversos autores citados neste trabalho, afirmam que o acesso as IES públicas são em sua maioria de jovens de classe $A$ e $B$, enquanto as IES particulares a grande maioria são de classe $C, D$ e E, nos revelando uma democracia frágil em relação a educação e igualdade de oportunidades no ensino e consequentemente desigualdade social.

Com a crescente expansão das IES no Brasil, oportunizada pela brecha da Constituição de 1988, fez com que diversas IES particulares surgissem no Brasil em número bem superior as IES públicas, revelando assim, uma educação com fins capitalistas no final do século XX. Apesar disto, o acesso ainda não era garantido aos jovens de classe baixa, foi aí que agentes governamentais interferiram com financiamentos para este acesso ser "garantido".

O jovem trabalhador busca uma ascensão de classe através do ensino superior, como meio facilitador, enfrentando jornadas exaustivas para conseguir seu diploma. Contudo, o jovem em seu último ano (geralmente) se depara com uma disciplina (pois está inserida na grade curricular dos cursos) de estágio supervisionado, que é uma fase muito importante em seu aprendizado teórico/prático de seu curso. Mas como poderá ser feito pelo jovem trabalhador que necessita de sua renda para custear seu estudo?

Apesar da autonomia garantida por diversas leis federais, as IES ainda parecessem não se voltar ao trabalhador/estudante e suas possibilidades de concluir seu curso com o aprendizado necessário (considerando a escolha de meios antiéticos para obter o estágio). O jovem não se vê preparado ou ao menos amparado pelas IES nesta fase de sua vida importante na busca de suas realizações, seja profissional ou pessoal, tornando falha o processo de ensino-aprendizagem do curso superior.

O estágio supervisionado, perante pesquisas realizadas, não é obrigatório como se considerava no começo das pesquisas, como apontado anteriormente, as leis específicas sobre o estágio o considera ou não (alguns cursos são obrigatórios, como área da saúde), cabendo as IES estruturar em seus cursos a grade curricular que fundamenta tais cursos, sendo garantida sua autonomia educacional. Ou seja, as IES possuem instrumentos legais para conseguir criar meios e alternativas, em especial, ao jovem trabalhador nesta fase importante do estágio supervisionado, pois vimos que o estágio supervisionado se configura de diversas formas, abrindo um leque de opções para o estudante realizar tal fase de seu curso.

De forma alguma, este artigo desvalorizou a questão do estágio e sua importância na formação dos discentes das IES. As discussões foram acerca da nova percepção social do século XXI e suas necessidades. A educação democrática clama uma reestruturação dos Projetos Políticos Pedagógicos das IES no Brasil, priorizando as particularidades locais, garantindo justiça social e oportunidade de crescimento social através das IES (meio "facilitador" compreendido pelos jovens) devendo ser revisto/reestruturado suas grades curriculares a questão do estágio supervisionado, meios e possibilidades de tal conclusão e semelhante aprendizado profissional. 


\section{REFERENCIAS}

BIANCHI, A. C. M.; ALVARENGA; M.; BIANCHI, R. Manual de orientação: estágio supervisionado. São Paulo: Pioneira Thomson Learning, 2002.

BRASIL. LDB: Lei de diretrizes e bases da educação: Lei 9.394/96 e legislação correlata. 2.ed. Rio de Janeiro: Roma Victor, 2007.

CAVALCANTE, M. C. L. P. Políticas de educação superior: acesso e permanência de estudantes trabalhadores dos cursos noturnos (1996-2006). 2008. 132 f. Dissertação (Mestrado em Educação) - Universidade Católica Dom Bosco, Campo Grande - MS.

COMIN, A. A.; BARBOSA, R. J. Trabalhar para estudar: sobre a pertinência da noção de transição escola-trabalho no Brasil. Novos estudos - CEBRAP, São Paulo, n. 91, p. 75-95, nov. 2011. Disponível em: <http://www.scielo.br/scielo.php?script=sci_arttext\&pid=S010133002011000300004\&lng=en\&nrm=iso>. Acesso

FAZENDA, I. C. A.; ... [et al.]; PICONEZ, S. C. B. (coord.). A prática de ensino e o estágio supervisionado. Campinas, SP: Papirus, 1991.

FURLANI, L. M. T. A claridade da noite: os alunos do ensino superior noturno. São Paulo: Cortez, 1998.

KULCSAR, R. O estágio supervisionado como atividade integradora. In: PICONEZ, Stela C. Bertholo (Org.). A prática de ensino e o estágio supervisionado. São Paulo: Papirus, 1991. p. 63-74.

PICONEZ, S. C. B. (Org.). A prática de ensino e o estágio supervisionado. Campinas, SP: Papirus, 1991.

ROTH, L.; et al. A estrutura do ensino superior no Brasil. Revista Gestão Universitária na América Latina - GUAL, Florianópolis, p. 111-126, set. 2013. ISSN 1983-4535. Disponível em: < https://periodicos.ufsc.br/index.php/gual/article/view/1983-4535.2013v6n3p111/25423 >. Acesso em: 08 mar. 2016. doi: http://dx.doi.org/10.5007/1983-4535.2013v6n3p111

TERRIBILI FILHO, A.; NERY, A. C. B. Ensino superior noturno no Brasil: história, atores e políticas. Revista Brasileira de Política e Administração da Educação. Universidade Federal do Rio Grande do Sul, v.25, n.1, p. 61-81, jan. /abr. 2009.

VARGAS, H. M.; PAULA, M. F. C. A INCLUSÃO DO ESTUDANTE-TRABALHADOR E DO TRABALHADORESTUDANTE NA EDUCAÇÃO SUPERIOR: DESAFIO PÚBLICO A SER ENFRENTADO. Avaliação, Campinas; Sorocaba, SP, v. 18, n. 2, p.459-485, jul. 2013. Disponível em: < http://periodicos.uniso.br/ojs/index.php?journal=avaliacao\&page=article\&op=view\&path[]=1590 \&path[]=1513 >. Acesso em: 21 jun. 2016. 